Article

\title{
Analysis of Yoga as an Inclusive Sport in Educational Contexts
}

\author{
David Moreno Molina *(D), Antonio Hernández Fernández ${ }^{\mathbb{D}}$ and Eufrasio Pérez Navío \\ Department of Pedagogy, University of Jaen, 23071 Jaén, Spain; antonio.hernandez@ujaen.es (A.H.F.); \\ epnavio@ujaen.es (E.P.N.) \\ * Correspondence: dmmolina@ujaen.es
}

Received: 8 May 2020; Accepted: 11 June 2020; Published: 17 June 2020

\begin{abstract}
Yoga is a growing sport in our current society, but we know little about it; what repercussions it has, what benefits its practice brings, repercussions in the educational environment, etc. Therefore, the objective of the article was to analyze if it is possible to design a scale of perception that relates yoga, teacher training, sport, benefits of yoga, and inclusive sport. The objective was to analyze and demonstrate the relationship between variables determining how the academic performance of the students can be improved, since the practice of yoga influences on diverse areas that cause changes at brain level in the students, and it can lead to better attentiveness, memory, etc. For this, a descriptive, explanatory, and correlational research project has been carried out with a quantitative methodology. The analysis sample was made up of 1575 subjects, distributed as follows: 1191 students of the Degree in Primary Education of the University of Jaén (from first to fourth course) and 384 teachers corresponding to different public centers of the province of Jaén. In order to investigate the objective, an operational table was created to construct the Likert scale. The original scale consisted of 20 items reporting an alpha of 0.826 , we achieved a reduction of four items, with a higher reliability (0.846), divided into five different dimensions. Likewise, construct validity was checked from a factorial analysis (KM0 $=0.787$, Bartlett 0.000$)$. The results of the research have been satisfactory, given that when analyzing the variables proposed in the initial objective, a high degree of correlation has been obtained between them, which supposes, applying it to the educational scope, a great incentive to carry it out in the educational centers, and, therefore, to improve the academic, personal, and social performance of the student.
\end{abstract}

Keywords: yoga; teacher training; sport; and inclusive sport

\section{Introduction}

In the XXI century, children live in a world full of distractions and technologies, which means that their degree of concentration is reduced; moreover, according to [1], 26\% of the Spanish population does not practice any sport. In addition, the obesity rate in Spain, according to Statista [1], is 22.3\%, a percentage that should be minimized, given the consequences it has on people's health, leading to diseases of various kinds, such as cardiovascular and respiratory diseases, etc. This fact made us perceive the need to promote physical activity due to the benefits that sport has at a cerebral, emotional, social, personal, academic, etc. level. Furthermore, according to [1], the children aged 11-17 years have a low profile of physical activity; around $80 \%$ of school-age children do not do the time recommended by the World Health Organization (WHO) to avoid health problems. However, research carried out by [2] showed that $74.35 \%$ of university students practiced some type of physical activity, and $34.38 \%$ of those surveyed said they practiced three or more times a week, which indicates a high prevalence of physical exercise. In this line, the most recent research provided by [3], affirmed that with the practice of yoga, a significant reduction of obesity is achieved, and in addition, it generates benefits at the 
respiratory level. The research revealed an enlightening fact about the importance of yoga in people, a review that referred to the psychological well-being of people. Also, the sample of the investigation affirmed that, through yoga, they were able to regulate their appetite, due to the fact that they overcame states of stress and anxiety with greater facility, which generated appetite to them at all times.

Adopting a sport perspective, and at the same time an educational one, yoga is presented as a method to promote sport practice, not only from a global perspective, but from a particular vision based on its methodological inclusion in educational centers. In this way, one of the objectives that yoga pursues is to promote the integral education of the students, avoiding possible diseases such as childhood obesity or cardiovascular problems, among others.

Yoga is a sport that is currently little known in society, especially by teachers for its pedagogical application. For this reason, the present investigation has been initiated in order to collect information about the repercussions that this sport has at personal, academic, and social levels, analyzing, for it, the relation between the variables of yoga, teacher training, sport, benefits of yoga, and inclusive sport. Conceptualizing the term yoga consists of the Sanskrit root "yug", which represents "to join", "to unite", "to put under the yoke". This refers to a set of techniques that pursue the harmonious union of body, mind, and spirit [4]. In today's society, yoga is defined as a physical activity, a therapeutic technique or a relaxation method, with the aim of achieving growth and physical, mental, emotional, and spiritual advancement [5].

We live in a stressful society, where mainly children spend five hours a day, from Monday to Friday, at school. In the afternoon they attend extracurricular activities (French, English, etc.), but when do they relax? When do they forget the stress of the classes and the routine in which they are involved? Stress, sometimes, derives impulsive behaviors, hyperactivity, negative behaviors, etc., perhaps yoga can play a fundamental role: it can be used as a tool, not only to do sport, but to achieve a social, emotional, and personal balance. According to [6], the effectiveness of yoga is increasing in what we know of its benefits, improving the full attention and meditation in those who practice it. In addition, Ref. [7] extracted, from research carried out with a group of people who were given yoga sessions during a temporary space, that stress levels were significantly reduced, while attention span increased. Ref. [8] came to consider yoga as a millenary practice, that is to say, an activity with a great historical projection, visualizing from different scopes the benefits that it entails. In addition, he pointed out the practice of yoga as an antidote to the very stressful society in which we live in the 21st century. For this author, at present, we live immersed in a society of comings and goings, continuously perceiving an emotional state of stress, but that, before it, what better way to fight it than with the practice of yoga.

Taking into account the studies carried out by [9], yoga generates benefits in the person at a physiological and psychological level. Supporting this argument, Ref. [10] stated that people who do physical activity at any level are involved in a series of beneficial changes at both the physiological and psychological levels. In addition, the practice of physical activity provides the person with a series of changes at the psychological level that will make him/her more likely to succeed in life, given the high impact this has on his/her day-to-day life. Likewise, the psychological variable is influenced by the practice of sport within the subject, through techniques such as inner dialogue, self-confidence, concentration, and motivation. These techniques are predicted to lead to a series of improvements, resulting in a better emotional state in the person with themself. Ref. [8] reaffirmed the above, specifying yoga as an antidote to improve personal and emotional level, since the continuous practice of this sport reduced, in high doses, the levels of stress and anxiety in the students, improving their personal well-being.

Ref. [11] stated that yoga is an effective pedagogical practice, with a number of positive behavioral changes in the learner. Supporting this argument [12] affirmed that the practice of yoga in the early educational stages demonstrates the importance of yoga within the educational system. Among the most noteworthy results provided by the research, we can highlight how the attention span of $98 \%$ of the students increased and, in addition, they improved their self-perception, self-esteem, are were more cheerful and spontaneous; $94 \%$ had a more positive thought with a better capacity to express their 
feelings, emotions, interests, etc.; $87 \%$ had less anxiety, facing the day-to-day better; $100 \%$ progressively discovered the motor possibilities of their own body, increased their autonomy, had better socialization capacity, had less aggressive behaviors, and had a better self-knowledge.

Now that the results of the most current and relevant research in the field to which we refer have been presented, we can clearly see the need for sport in children's lives in order to avoid states of discouragement, frustration, etc., and its contribution to the aim of improving their performance capacity as much as possible, on an academic, personal, and social level. If we add the current relevance of yoga to the importance of sport in people's lives, in this case the students, this can become a fundamental link to teach yoga in schools; that is, the practice of yoga in certain school moments gives the person a series of tools, attitudes, and thoughts that will make them face the day from a better perspective. Ref. [13] exposed that the yoga programs that have been implemented in the schools of the United States have brought promising results about the benefits that the practice of yoga has in the students, reporting benefits at all levels-personal, social, emotional, etc. Ref. [14] implemented yoga programs in 15 schools in South Carolina, obtaining as a conclusion the best perception, in first person, of the students in terms of concentration, emotional regulation, flexibility, breathing, and school work.

According to [15], the continuous demand of parents on their children to achieve academic performance, school work, and extracurricular activities is immersing the students in what he called an educational stress. This fact has become a very important item to consider, since stress is closely related to the academic performance of students, and not only with this aspect, but with something more important, which is health and well-being. Within this process, yoga plays a fundamental role, since its practice reduces the high doses of stress that this routine generates in the students. In front of this problem raised by [15], Ref. [16] exposed that students who have practiced yoga reported to have a considerably higher welfare, a lower perceived stress, a lower body mass index, and higher rates of positive behaviors in health matters. In addition, Ref. [15] stated that yoga provided positive thinking in learners, while burnout decreased.

In conclusion, people who actively practice yoga show a better emotional state, better social skills, etc. This fact emphasizes the importance of physical activity in a person's daily life, with the only objective of improving their quality of life.

\section{Materials and Methods}

The research adopted was of a nonexperimental, descriptive, explanatory, and correlational type. A Likert scale was used as a data collection instrument, which was subjected to a validation analysis through the coefficient of expert competence, the instrument's content validity, and the Fleiss kappa. The confirmation of its validity was done with a pilot test. The validation of the construct was done with an exploratory factor analysis. The reliability of this instrument was developed through the internal consistency of intercorrelation and that of the halves. The hypothesis contrast was made with the Kruskal-Wallis test that determined the type of correlation we were going to make (Pearson or Spearman) and the possibility of making an ANOVA of a factor (group). Finally, we subjected the scale to a confirmatory factor analysis (structural equation modeling).

\section{Research problem}

The research problem raised was: Can a scale be designed and validated to establish the relationship between yoga, teacher training, and sport on the benefits of yoga and inclusive sport?

\section{Objectives}

General: To analyze if it is possible to design a scale of perception that relates yoga, teacher training, sport, benefits of yoga, and inclusive sport.

Specific:

1. To verify the knowledge that is had about yoga in university students and primary education teachers. 
2. To show the perception that research subjects have about the benefits of yoga.

3. To identify the characteristics of inclusive sport in a school context.

4. To know the perception that university students and teachers have about the teacher training in inclusion, yoga, and inclusive sport.

5. To find out the perspective that participants have in research on sport and inclusion.

\section{Hypothesis}

The following null hypothesis was defined:

H0-A scale cannot be designed and validated to measure the relationship between yoga, teacher training, and sport on the benefits of yoga and inclusive sport.

\section{Procedures}

Prior to the development of the research with the students of the Degree of Primary Education of the University of Jaén and a sample of teachers of the province in which the university of reference is inserted, the appropriate permissions were requested, guaranteeing at all time the anonymity of the subjects of research.

\section{Participants}

We considered the population constituted by the university students of the grades of primary education (from first course to fourth) of an Andalusian university, concretely of the University of Jaén, and the teachers of primary education of the province of Jaén (Andalusia). This population was constituted by 1575 subjects. The Likert scale, after several absences and dropouts, was finally answered by 299 (4th), 294 (3rd), 298 (2nd), 300 (1st), a total of 1191 subjects, of which, 78\% were female and $22 \%$ male, the age of the subjects corresponded, in its average, with that corresponding to the academic group, as reflected in Table 1. For the calculation of the sample of teachers, the population of primary school teachers in the province was taken, a total of 9878 subjects, which, applying the formula for the calculation of the sample in finite populations, left a sample of 384 research subjects, of whom 76 percent were female and 24 percent male, the average age of the subject under investigation being 42 years. The distribution of the questionnaires was carried out in the first semester of the 2019-2020 academic year.

Table 1. Sample characteristics.

\begin{tabular}{ccccc}
\hline \multicolumn{2}{c}{ Students of Primary Education (University of Jaén) } & \multicolumn{2}{c}{ Primary School Teachers in the Province of Jaén } \\
\hline Course & $\begin{array}{c}\text { Number of } \\
\text { Participants }\end{array}$ & $\begin{array}{c}\text { Age of } \\
\text { Participants }\end{array}$ & Total Participants & Selected Sample \\
\hline $1^{\circ}$ & 300 & 18.2 & 9878 participants & 384 participants \\
$2^{\circ}$ & 298 & 19.1 & & \\
$3^{\circ}$ & 294 & 20.3 & \\
$4^{\circ}$ & 299 & 21.3 & \\
\hline \multicolumn{4}{c}{ Source: own elaboration. }
\end{tabular}

\section{Dimensions and variables}

The dimensions we considered, extracted taking into account the theoretical framework, problem, and specific objectives, were: A. yoga, B. benefits of yoga, C. inclusive sport, D. teacher training, and E. sport.

Consequently, we established the following variables:

- The dependent variables were: the benefits of yoga, inclusive sport;

- $\quad$ The independent variables were: yoga, teacher training, sport. 


\section{Instrument}

The Likert scale was constructed with an operationalization table (Table 2), according to the specific objectives and dimensions established from the theoretical framework. Five dimensions were established, with a total of items of thirty, with a graduation from 1-very much in disagreement, 2-disagreement, 3-indifferent, 4-according to 5-very much in agreement, (1-5).

Table 2. Table of operationalization.

\begin{tabular}{|c|c|c|}
\hline Specific Goals & Dimensions & Likert \\
\hline $\begin{array}{l}\text { 1. To verify the knowledge } \\
\text { that one has about yoga in } \\
\text { university students } \\
\text { and primary } \\
\text { education teachers. }\end{array}$ & $\begin{array}{c}\text { A. Yoga } \\
\text { Base Authors: Moreno } \\
\text { (2020), Hernández (2020), } \\
\text { and Pérez }(2020)\end{array}$ & $\begin{array}{l}\text { A1. You have great knowledge about yoga } \\
\text { A2. Yoga can be practiced both individually and } \\
\text { in groups } \\
\text { A3. Yoga can be practiced in schools } \\
\text { A4. Yoga is a sport in which different postures, } \\
\text { vocal and visual stimuli are used } \\
\text { A5. Teachers consider that yoga should be } \\
\text { practiced in educational centers } \\
\text { A6. Yoga is accessible to everyone }\end{array}$ \\
\hline $\begin{array}{l}\text { 2. To show the perception } \\
\text { that research subjects have } \\
\text { about the benefits of yoga. }\end{array}$ & $\begin{array}{l}\text { B. Benefits of yoga } \\
\text { Base Authors: } \\
\text { Moreno (2020), Hernández } \\
\text { (2020), and Pérez (2020) }\end{array}$ & $\begin{array}{l}\text { B7. Yoga promotes socialization } \\
\text { B8. Yoga promotes attention and memory } \\
\text { B9. Yoga improves academic performance } \\
\text { B10. Yoga reduces impulsive behaviors } \\
\text { B11. Yoga improves brain areas related to language } \\
\text { B12. The practice of yoga improves } \\
\text { positive thinking } \\
\text { B13. Yoga improves brain neuroplasticity } \\
\text { B14. Yoga helps to have a better emotional control }\end{array}$ \\
\hline $\begin{array}{l}\text { 3. Identify the } \\
\text { characteristics of inclusive } \\
\text { sport in a school context. }\end{array}$ & $\begin{array}{c}\text { C. Inclusive Sport } \\
\text { Base Authors: } \\
\text { Moreno (2020), Hernández } \\
\text { (2020), and Pérez (2020) }\end{array}$ & $\begin{array}{l}\text { C15. Inclusive sport promotes the active role } \\
\text { of students } \\
\text { C16. Inclusive sport helps to counteract } \\
\text { competitiveness } \\
\text { C17. Inclusive sport improves the quality } \\
\text { of education } \\
\text { C18. The basis of inclusive sport is to participate on } \\
\text { equal terms } \\
\text { C19. All teachers should be involved in } \\
\text { inclusive sport } \\
\text { C20. Inclusive sport promotes values of acceptance } \\
\text { of differences }\end{array}$ \\
\hline
\end{tabular}

4. To know the perception that university students and teachers have about teacher training in inclusion, yoga, and inclusive sport.

D21. I think I have sufficient training in inclusion D22. I consider myself capable of promoting inclusion in the educational field D23. I consider myself capable of giving yoga classes in the educational field D24. I feel able to promote inclusive sport D25. I consider myself sufficiently trained in inclusive sports

E26. I believe that sport should always be inclusive E27. Promoting sport is a task for all teachers

5. To find out what perspective participants in sport research have on physical education and inclusion.
E. Sport

Base Authors: Moreno (2020), Hernández (2020) y Pérez (2020)
E28. Sport should not be limited to the area of physical education

E29. Sport improves people's physical and mental quality E30. Sport generates states of happiness through its practice 


\section{Validity of content}

The judgement of validity was made by $10 \mathrm{PhD}$ specialists in the field [17] in order to validate the scale; the coefficient of expert competence, the content validity of the instrument, the interobserver match analysis, the match coefficient between judges, and the adequacy of the items to the adopted content validity criteria have been calculated. Expert competence coefficient (K): $\mathrm{K}$ was calculated from the knowledge coefficient $(\mathrm{Kc})$ and the argumentation coefficient $(\mathrm{Ka})$, obtaining a value of 0.89 of competence in the matter, which was based on [18]. Content validity of the instrument (CVI): the content validity of the instrument was carried out through the Lawshe method [19], modified by Tristan [20], which shows us that as a whole the items are valid when reaching a global validity index (CVI) of 0.93. Fleiss kappa: the interobserver agreement analysis was supported by the Fleiss kappa index, obtaining a result of 0.940 (Sig 0.000), which corresponds to an almost perfect agreement among the experts [21].

\section{Checking the validity of the instrument}

On the other hand, a pilot test was carried out on a subgroup of the sample population, with the aim of reviewing comprehension difficulties, detecting questions that raised doubts, etc., using the appropriate checklist [22]. Likewise, the results provided by the pilot test were satisfactory, so the content instrument was considered validated.

\section{Data analysis}

The research tool used for data analysis was IBM SPSS Statistics v25 and Lisrel 8.80.

\section{Results}

\subsection{Constructive Validity (Exploratory Factor Analysis)}

The factorial analysis technique that we applied in our research followed the guidelines set out in the following stages, which were of an exploratory nature [22-24]:

\section{Study of the correlation matrix}

The correlation matrix study was also assessed to confirm whether our data were appropriate for carrying out a factorial analysis. To check this, we have used the Kaiser-Meyer-Olkin measure of sampling adequacy (KMO coefficient), in our case the value was 0.787, following Kaiser [25], the value was acceptable. Barlett's sphericity test was significant $(0.000)$, the determinant had a value of $1.662 \times 10^{-7}$, so we continued with the analysis.

\section{Extraction of the factors}

The resulting table of communalities showed us that the factors had a value greater than 0.517 , so it was not necessary to eliminate any item from the factorial analysis. The best represented items were: E29 (0.911) — sports improve the physical and mental quality of people—and E30 (0.842)—sport generates states of happiness through its practice. The worst represented item was: B13 (0.517). Yoga improves cerebral neuroplasticity.

\section{Factor rotation}

We opted for the Varimax rotation that optimizes the factorial loads so as to obtain the most extreme loads possible in the factors (high and low), in our case they were the first eight factors, which explained $66.018 \%$ of the accumulated variance.

\section{Study of factorial scores}

Once the factorial scores and the analysis of variance explained and accumulated were calculated, as well as the determination of factors and distribution of items according to the highest level of saturation by factors, we could build the table of items integrated in each factor (Table 3). 
Table 3. Factors and items.

\begin{tabular}{cll}
\hline Factor & \multicolumn{1}{c}{ Items } & \multicolumn{1}{c}{$\begin{array}{c}\text { Items Integrated in Each Factor } \\
\text { of the Questionnaire }\end{array}$} \\
\hline \multirow{2}{*}{ I } & A. Yoga. & A1, A2, A3, A4, A5, A6 \\
& B. Benefits of yoga. & B7, B8, B9, B10, B11, B12, B13, B14 \\
& C. Inclusive sport. & C15, C16, C18, C20 \\
& D. Training for teachers. & D22, D24 \\
& E. Sport. & E26, E28, E29, E30 \\
\hline II & E. Sport. & E27 \\
\hline \multirow{2}{*}{ III } & C. Inclusive sport. & C17, C19 \\
& D. Teacher training. & D21, D23, D25 \\
\hline
\end{tabular}

Source: own elaboration.

Internal consistency of intercorrelation of elements (Cronbach's Alpha)

The reliability of the original scale (30 items) was 0.826 (Cronbach) "good" (Table 4). We calculated Cronbach's alpha of factor 1: 0,901 (24 items), rating "excellent". The factor 1 presented a higher reliability than the original scale itself, getting a final scale of 24 items, reducing six items.

Table 4. Reduced scale.

\begin{tabular}{l} 
Items \\
\hline A1. You have great knowledge about yoga \\
A2. Yoga can be practiced both individually and in groups \\
A3. Yoga can be practiced in schools \\
A4. Yoga is a sport in which different postures, vocal, and visual stimuli are used \\
A5. Teachers consider that yoga should be practiced in educational centers \\
A6. Yoga is accessible to everyone \\
B7. Yoga promotes socialization \\
B8. Yoga promotes attention and memory \\
B9. Yoga improves academic performance \\
B10. Yoga reduces impulsive behaviors \\
B11. Yoga improves brain areas related to language \\
B12. The practice of yoga improves positive thinking \\
B13. Yoga improves brain neuroplasticity \\
B14. Yoga helps to have a better emotional control \\
C15. Inclusive sport promotes the active role of students \\
C16. Inclusive sport helps to counteract competitiveness \\
C18. The basis of inclusive sport is to participate on equal terms \\
C20. Inclusive sport promotes values of acceptance of differences \\
D22. I consider myself capable of promoting inclusion in the field of education \\
D24. I feel able to promote inclusive sport \\
E26. I believe that sport should always be inclusive \\
E28. Sport should not be limited to the area of physical education \\
E29. Sport improves people's physical and mental quality \\
E30. Sport generates states of happiness through its practice \\
\hline
\end{tabular}

Source: own elaboration.

Internal consistency of the halves (Spearman-Brown/Guttman)

The value of the Spearman-Brown correlation coefficient will always be between 0 and 1 . In our case, for equal length it was 0.850 , which showed reliability in the data. The coefficient of two halves of Guttman was 0.850 , which means that there was reliability in the data.

\subsection{Correlation Analysis}

To carry out the correlation, we subjected the Likert scale to the Kruskal-Wallis test, which resulted in the conservation of the null hypothesis, so that the data followed a normal distribution, thus using 
the Pearson correlation. Next we show the correlations between items that have significant value $(0.05)$

(Figures 1-5):

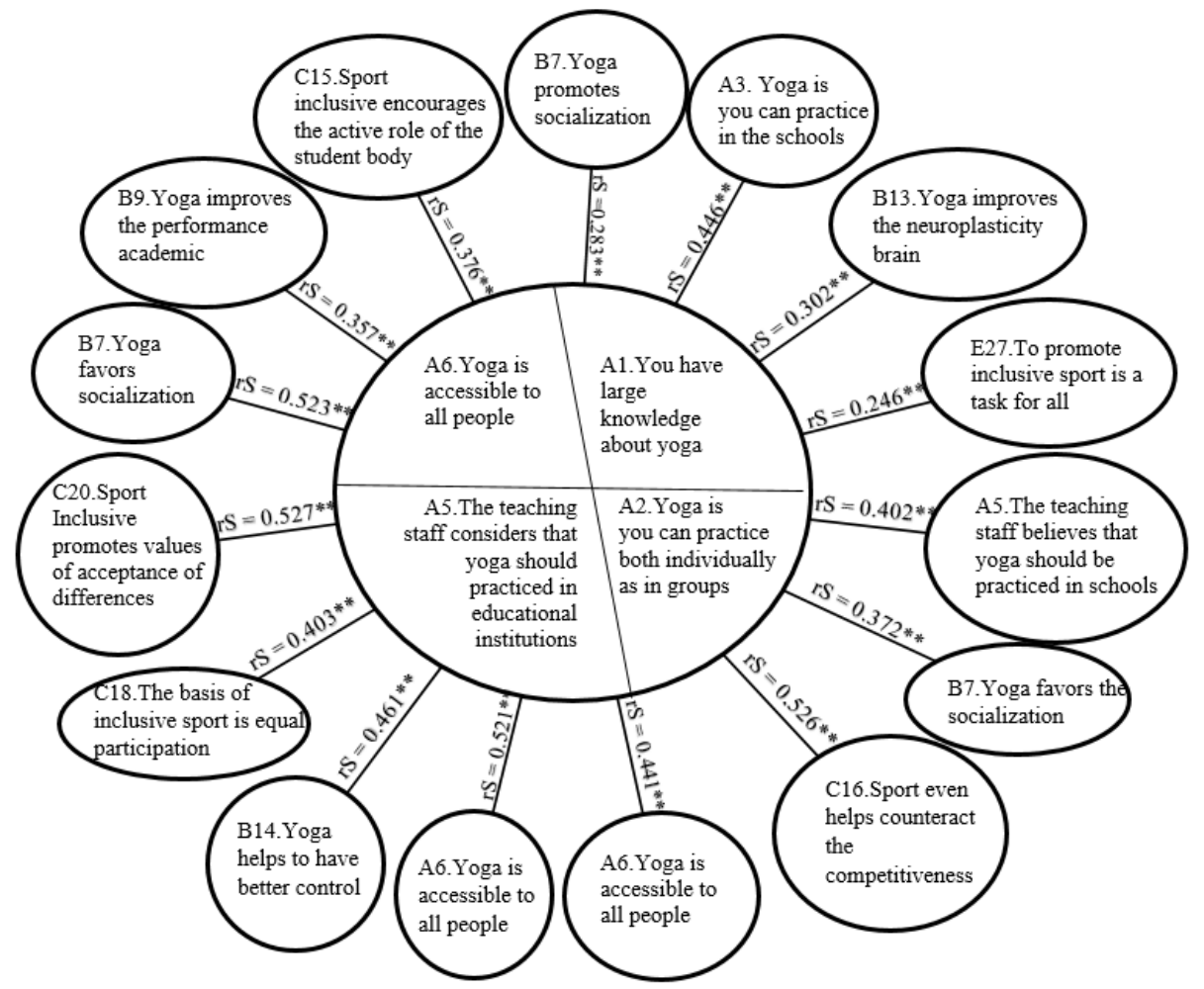

Figure 1. Most significant correlations of the variable A. Source: own elaboration.

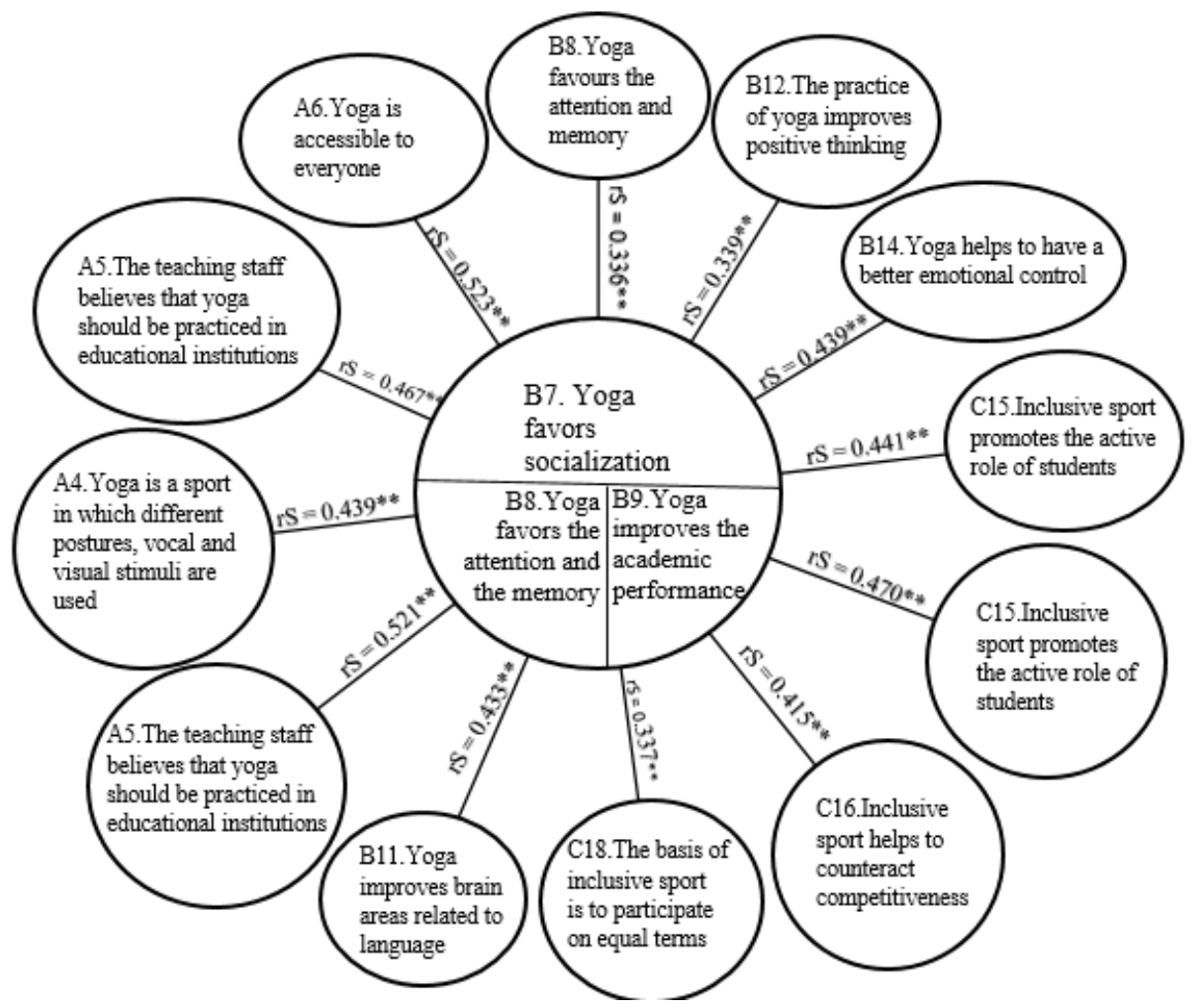

Figure 2. Most significant correlations of the variable B. Source: own elaboration. 


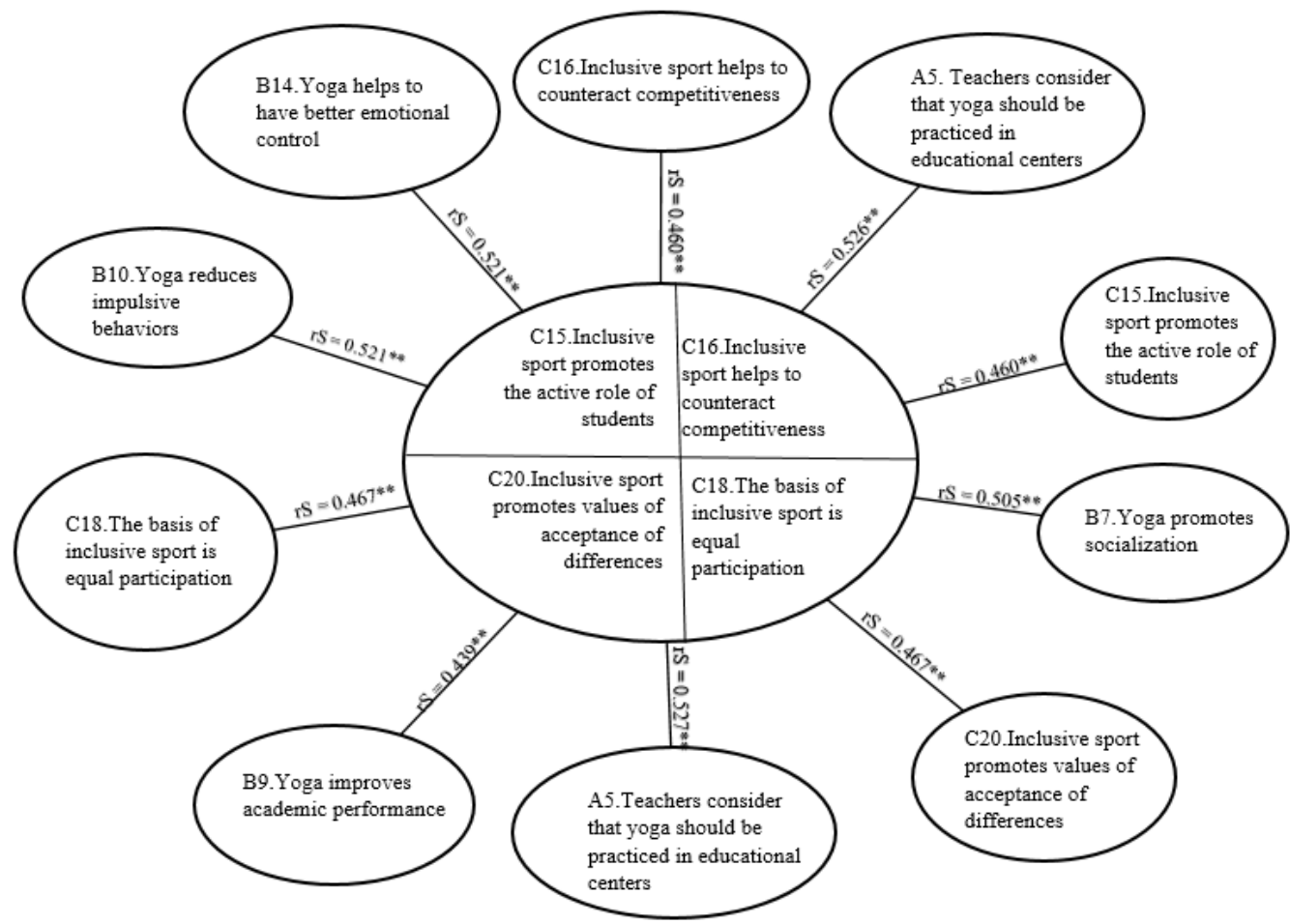

Figure 3. Most significant correlations of the variable C. Source: own elaboration.

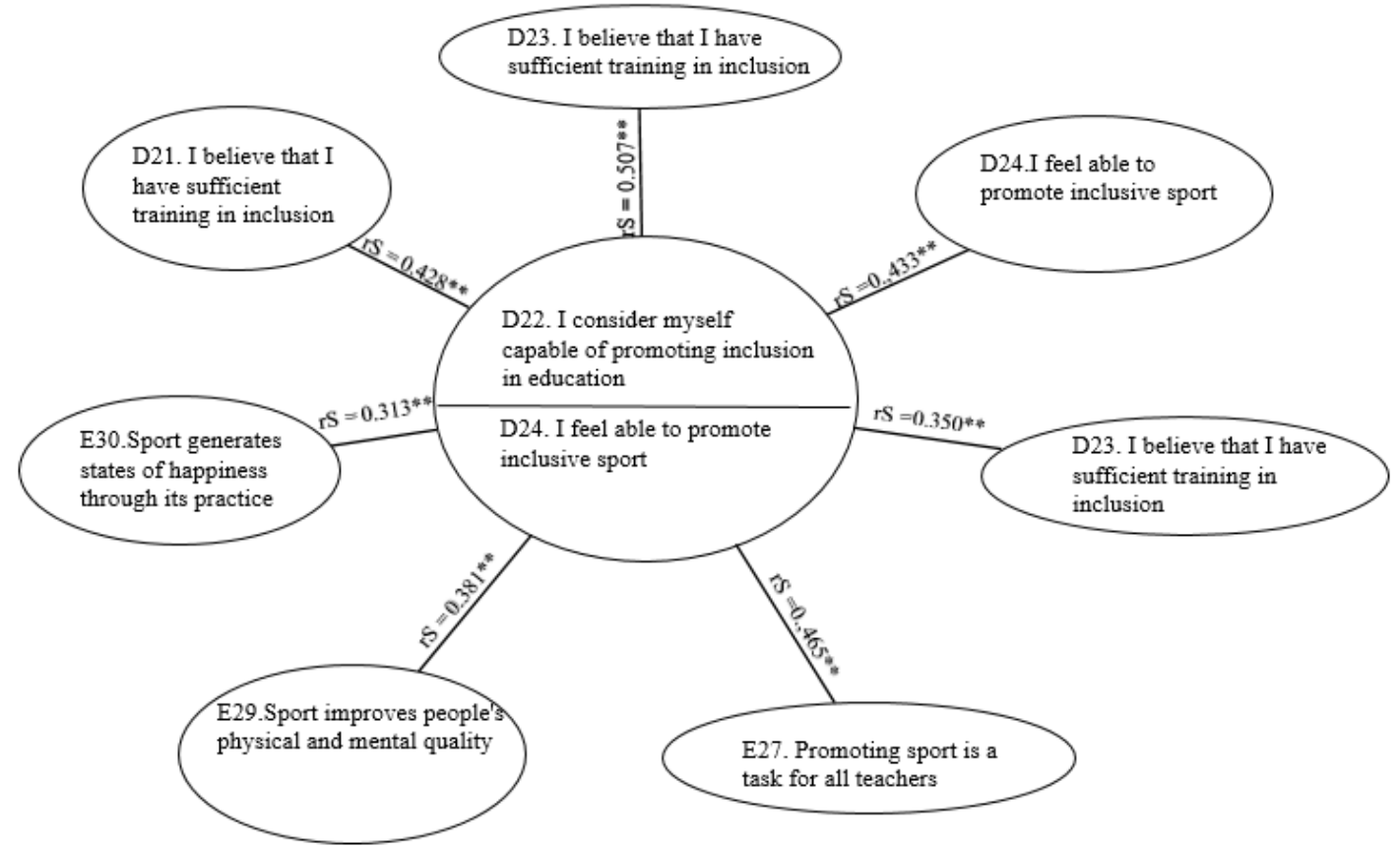

Figure 4. Most significant correlations of the variable D. Source: own elaboration. 


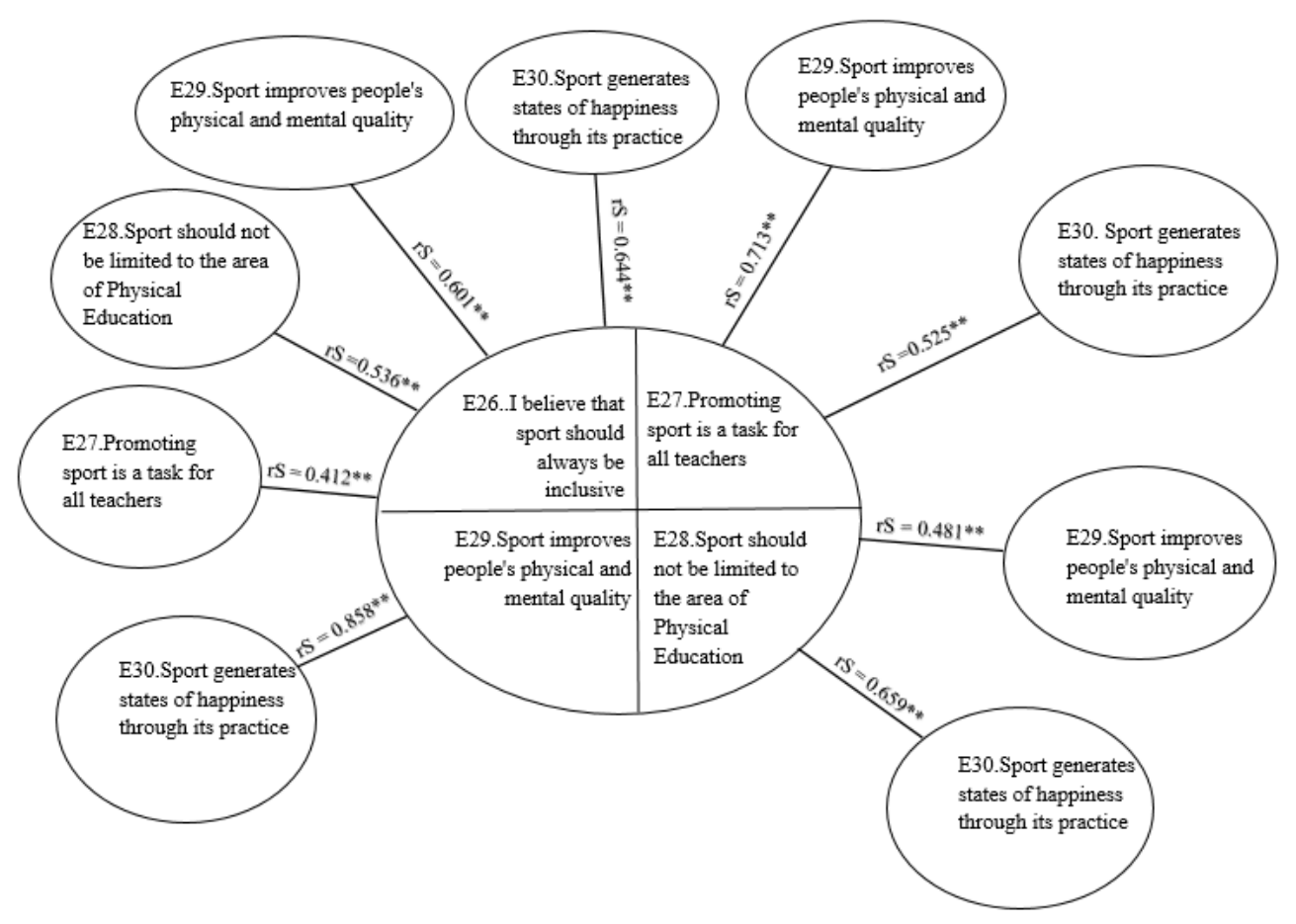

Figure 5. Most significant correlations of the variable E. Source: own elaboration.

\subsection{Hypothesis Contrast (ANOVA)}

The analysis of variance (ANOVA) tests the hypothesis that the means of the four samples are equal. The null hypothesis states that all means are equal, while the alternative states that at least one is different [26]. To perform the ANOVA test we needed a grouping variable (factor Group) and the four independent samples. First, we calculated Levene's statistic to contrast the hypothesis of population variance, the result is shown in Figure 6, having to reject the null hypothesis.

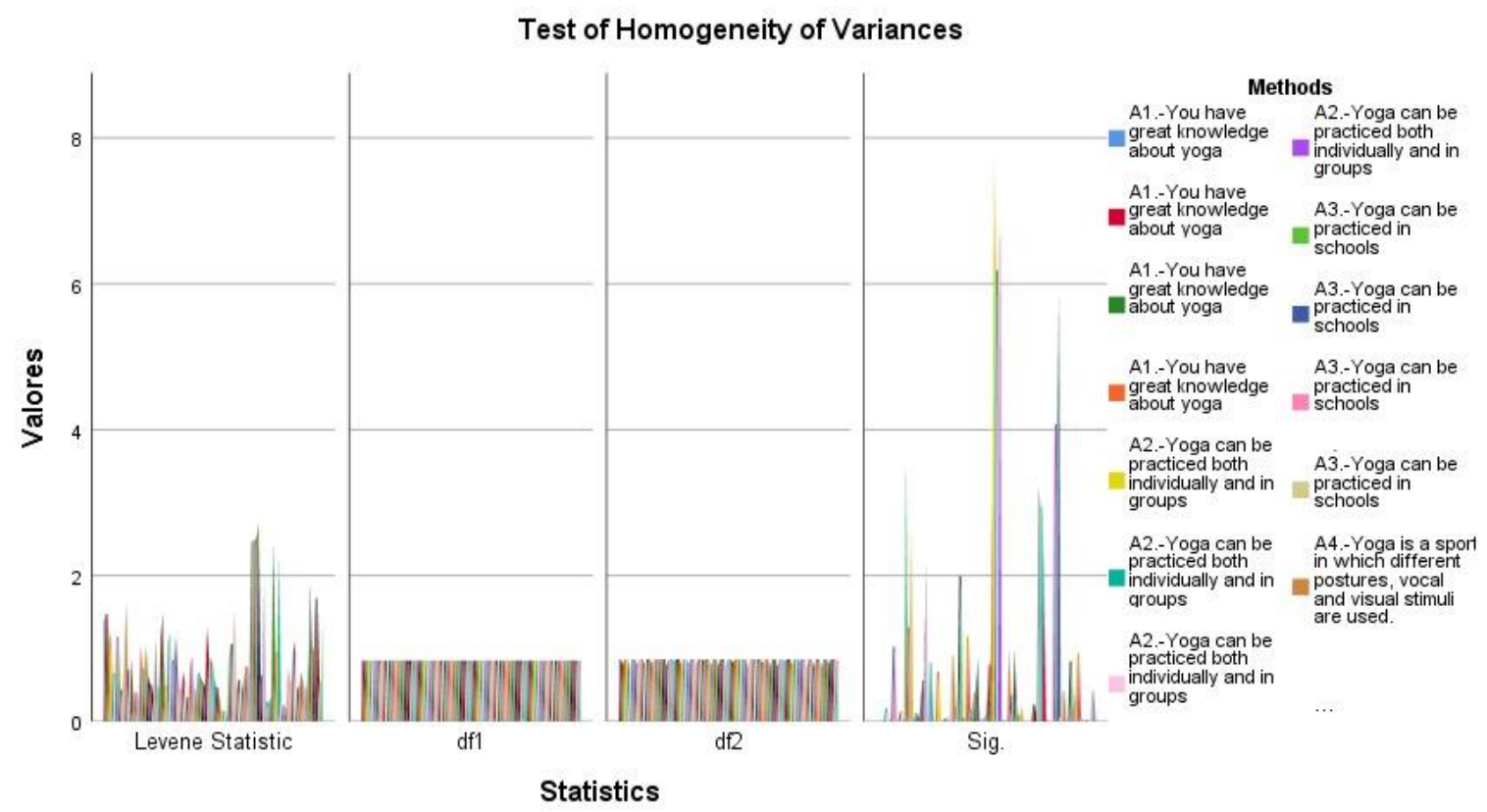

Figure 6. Homogeneity of variances test. Source: own elaboration.

We proceeded to calculate the ANOVA of a factor, as can be seen in the following Figure 7. 


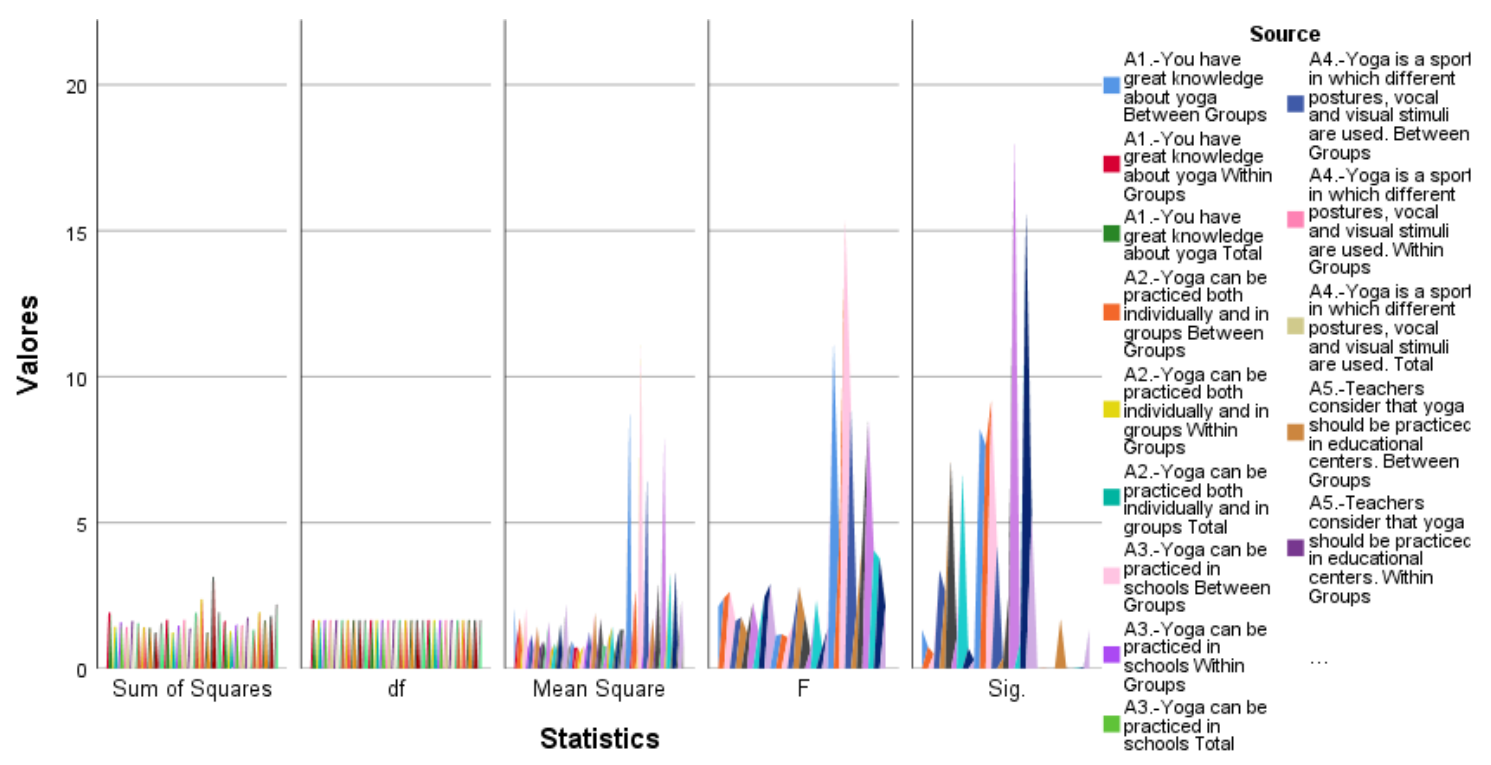

Figure 7. ANOVA of a factor. Source: own elaboration.

Analysis of significant differences in the data (ANOVA) according to the degree of significance $(<0.05)$.

Item A1 (0.042)—has great knowledge about yoga—showed significant differences, in a staggered way from the indifferent valuation of the students in 1st (3.9), 2nd (4.01), and 3rd (4.06) groups, and up to the teachers (4.12), who agreed in having great knowledge about yoga.

Item A2 (0.024) - yoga can be practiced both individually and in groups- showed that from the 1st to 4 th groups they were very much in agreement, but there was a gradual increase of the average from 4.2 to 4.49 , being the teachers in a score of 4.35 that placed them with an equivalent score to the students of the 2nd group (4.36).

A3 (0.016) - yoga can be practiced in schools. Students from the 1st (3.8) to 4th (3.9) groups were indifferent-according to the statement, teachers with a score of 3.77 were at a low level with the 1st group of students (3.7).

B7 (0.033) - yoga favors socialization. We had a gradual increase from the students of the first group (3.9) to the teachers (4.10), in a linear way being from indifferent, according to the statement.

B9 (0.022)-yoga improves the academic performance. The subjects of the 1st (3.6) group showed themselves indifferent, the result goes up to the 4th course that showed themselves indifferent accordingly (3.7), while the teachers also showed themselves indifferent, with a score of 3.6.

B10 (0.009) - yoga reduces impulsive behaviors. The response to this item was indifferent, however, we had a gradual increase from 1st (3.57) to teachers (3.79), which was close to agreement.

C15 (0.011) -inclusive sport encourages the active role of students. The response to this item was indifferent. We had a gradual increase from 1st (3.88) to 3rd (4.00), 4th (4.04), and teachers (4.07), who were in agreement.

C18 (0.028) - the basis of inclusive sport is to participate on equal terms. Students in grades 1-4 agreed, $(4.01,4.08,4.13,4.18)$, with teachers (4.05) closest to the answers given by students in grade 2 .

D21 (0.000)-I think I have sufficient training in inclusion. The subjects from the 1st (3.2) to 4th groups (3.3) showed an indifferent response, with the teachers being closer to agreeing (3.66).

D22 (0.001) - I consider myself capable of promoting inclusion in the educational field. We had a gradual upwardly indifferent response towards agreement, from 1st (3.5) to 4th (3.68), with teachers giving a response of 3.79 .

D23 (0.000) - I consider myself capable of giving yoga classes in the educational field. Subjects from the 1st to 4th groups showed an increase from 3.11 to 3.22, with an indifferent response, while teachers were at a score of 3.57 . 
D24 (0.000) - I feel capable of promoting inclusive sport. Subjects from the 1st to 4th groups showed a promotion from 3.43 to 3.57 , with an indifferent response, teachers were at a score of 3.79 .

E26 (0.000) - I believe that sport should always be inclusive. We had a gradual promotion, in the answer of agreement, from 1st (4.15), 4th (4.32), and teachers (4.40).

E27 (0.000)-fostering sport is a task for all teachers. The response from 1st to 4 th grades was indifferent (3.7 to 3.9), teachers showed agreement (4.18).

E28 (0.001) - sports should not be limited to the area of physical education.

E29 (0.002)—sport improves the physical and mental quality of people.

E30 (0.042)—sport generates states of happiness through its practice.

\subsection{Descriptive Analysis}

Dimension A (yoga): when it was asked if the participating subjects considered themselves to have enough knowledge about yoga, we observed that they agreed with this statement $(\bar{x}=4.06)$, as well as it was stated that the teachers consider that yoga is necessary to be included in the educational centers $(\bar{x}=4.07)$, as well as they think that it is a discipline that can be practiced both individually and in groups $(\overline{\mathrm{x}}=4.38)$. Even so, in reference to the dimension of yoga, with average values below four and above 3.5, we found the statements that yoga can be practiced in schools $(\bar{x}=3.86)$; yoga is a sport in which different postures, vocal, and visual stimuli are used $(\bar{x}=3.93)$; and yoga is accessible to everyone $(\bar{x}=3.54)$ to be between the indifferent response variable and in agreement.

Dimension B (benefits of yoga): respondents agreed that yoga helps to have better emotional control $(\bar{x}=4.02)$ and that its practice leads to improvements in the socializing process $(\bar{x}=4.04)$. We also found values close to 4.00 , so the average response was closer to confirmation-agreeing with ideas such as the improvement of academic performance through yoga $(\bar{x}=3.67)$, the reduction of impulsive behaviors through yoga $(\bar{x}=3.69)$, yoga improves the brain areas related to language $(\bar{x}=3.61)$, as well as the improvement of brain neuroplasticity $(\bar{x}=3.69)$. However, with more values of responses closer to 3 , this value being indifferent, respondents reported that yoga promotes attention and memory $(\bar{x}=3.48)$, as well as an improvement in positive thinking $(\bar{x}=3.40)$.

Dimension C (inclusive sport): for the questions in which it was stated that inclusive sport improves educational quality $(\bar{x}=3.25)$, as well as that inclusive sport should involve all teachers $(\bar{x}=3.10)$, the average response values of the respondents were closer to 3.00 , which made us see that both statements were indifferent. However, with values of around 4.00 , and with respondents agreeing with this statement, inclusive sport was seen as promoting the active role of students $(\bar{x}=4.00)$, helping to counteract competitiveness $(\bar{x}=3.98)$, encouraging participation on equal terms $(\bar{x}=4.09)$, and promoting values of acceptance of differences $(\bar{x}=4.07)$.

Dimension D (teacher training): when we referred to the teacher training dimension, we obtained the significantly lower values of all the dimensions. The average values of the responses were between indifferent, according to the dimensions posed: I consider myself sufficiently trained in inclusion $(\bar{x}=3.41)$, I consider myself capable of promoting inclusion in the educational field $(\bar{x}=3.67)$, I consider myself capable of giving yoga classes in the educational field $(\bar{x}=3.28)$, I consider myself capable of promoting inclusive sports $(\overline{\mathrm{x}}=3.58)$, and I consider myself sufficiently trained in inclusive sports $(\bar{x}=3.07)$.

Dimension E (sport): in reference to sport, the response averages by the respondents were around the value of 4 , in agreement. Therefore, respondents considered that sport should always be inclusive $(\bar{x}=4.29)$, promoting sport is a task for all teachers $(\bar{x}=3.95)$, sport should not be limited to the area of physical education $(\overline{\mathrm{x}}=4.22)$, sport improves people's physical and mental quality $(\overline{\mathrm{x}}=4.35)$, and sport generates states of happiness through its practice $(\bar{x}=4.21)$.

\subsection{Confirmatory Factor Analysis}

The SEM methodology consisted of a series of phases according to Kaplan [27] and Kline [28] that we will specify in four phases. 
Phase I. Specification of the Measurement Model

In this stage, the latent features and the dimensions that represent them are established as variables of interest in a substantive theory. This stage is of a conceptual nature and in it the structure of relations between the latent variables represented by the dimensions of the instrument and the answers to the context questionnaire's reagents are formulated. The conceptual model of the Likert scale obtained from the exploratory factor analysis was composed of 24 observed variables that were grouped into five dimensions.

Phase II. Identification. Computational Implementation of the System of Structural Equations

To determine if the model is identified we must calculate the degrees of freedom (gl). In our case the value was 196, so we can say that the model was overidentified.

Phase III. Evaluation of Parameters

The model estimation phase includes a graphic representation of the theoretical-conceptual structure of the instrument under analysis. This representation is the basis for the formulation of the reproduced matrix that will be compared with the derived matrix. For the Likert scale, the graphic representation is shown in the Figure 8, in which the ovals represent the five latent variables (constructs) and the boxes of the 24 observed variables, which together make up the dimensionality of the instrument.

As for the regression coefficients between the latent and observed variables, the interpretation is as follows.

Dimension A (yoga):

Highest influence of the latent variable was on A05 (0.68). The teachers considered that yoga should be practiced in the educational centers. Lesser influence of the latent variable was on A05 (0.68) and A01 (0.36) - you have great knowledge about yoga.

Dimension B (benefits of yoga):

More influence of the latent variable was on A01 (0.36) — you have great knowledge about yoga and B10 (0.55)—yoga reduces impulsive behavior. Lesser influence of the latent variable was on B10 (0.55) and B13 (0.44) - yoga improves neuroplasticity of the brain.

Dimension C (inclusive sport):

More influence of the latent variable on C16 (0.59)-inclusive sport helps to counteract competitiveness. Lesser influence of the latent variable on C16 (0.59)-inclusive sport helps to counteract competitiveness, C15 (0.44) -inclusive sport encourages an active role for students, and C18 (0.44)—inclusive sport is based on equal participation.

Dimension D (teacher training):

Greater influence of the latent variable on D24 (0.63) - I feel able to promote inclusive sport and I feel capable of promoting inclusive sport-D22 (0.41). I feel able to promote inclusion in the field of education.

Dimension E (sport):

Greater influence of the latent variable was on E30 (0.91) — sport generates states of happiness through its practice. Less influence of the latent variable was on E30 (0.91) and E26 (0.54) - I believe that sport should always be inclusive.

Interdimensional relationships.

A-B (0.85), A-C (0.92), A-D (0.37), A-E (0.39)

B-C (0.84), B-D (0.42), B-E (0.39)

C-D (0.35), C-E (0.33)

D-E (0.41)

The strongest relationship between the latent variables was given by

A (yoga)-C (inclusive sport) (0.92)

A (yoga)-B (benefits) (0.85) 
B (benefits)-C (inclusive sport) (0.84)

The lowest ratio is given by:

$\mathrm{C}$ (inclusive sport)-E (sport) (0.33)

$\mathrm{C}$ (inclusive sport)-D (teacher training) (0.35)

Phase IV. Evaluation of the Adjustment Application of Indexes and Criteria of Goodness of Fit

In this stage, we used indices and criteria of goodness of fit to relate the validated evidence to the dimensional structure of the instrument being evaluated: X2/gl (1.00). IAA: GFI (0.91), RMSEA (0.074), NCP (1711.10), SRMR (0.038), RMS (0.0057), ECVI (1.34). IAI: AGFI (0.86), IFI (0.96), NFI (0.95), TLI/NNFI (0.94), RFI (0.93), CFI (0.96). IP: PNFI (0.68), PGFI (0.59), AFGI (0.86).

As you can see, the criteria for all goodness of fit indices were met, so the model was fully confirmed.

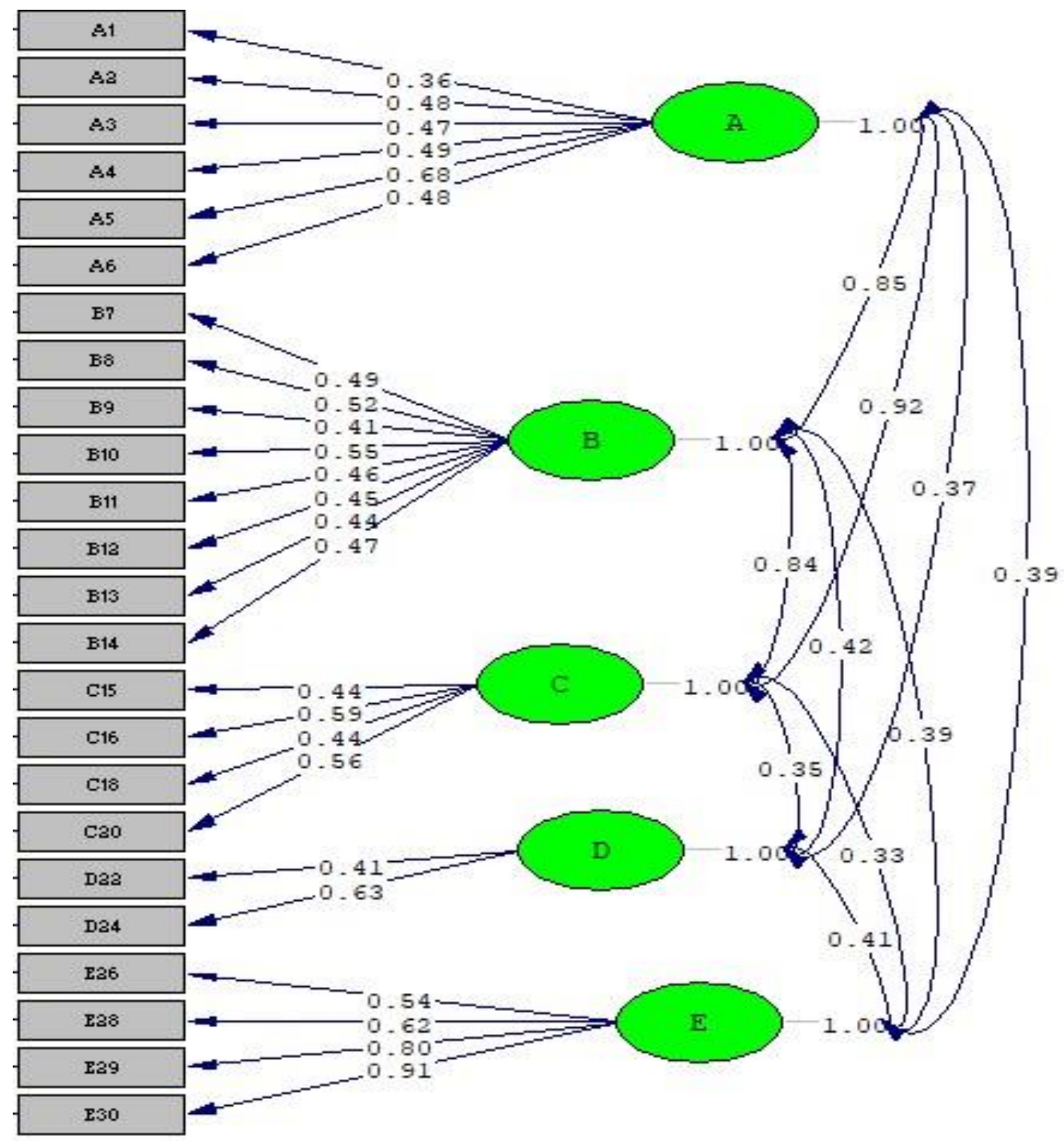

Figure 8. Graphic representation of the natural measurement model of the Likert scale. Source: own elaboration. 


\section{Discussion}

According to the results found in the study, a high degree of significance and relationship between variables can be deduced, so that from the deductions obtained, it can be seen that the practice of yoga generates in the student a series of strategies and techniques that will serve to improve both the academic area and the personal or social area. This research is verified with the results obtained in [29], which stated that yoga improves memory and cognitive functions in the target subjects. Also, in this line, given the potential benefits of yoga for populations living with high stress, it is important to develop more outreach efforts and provide accessible, acceptable, and affordable opportunities for the practice of yoga [30]. First-person students reported that the practice of yoga improved social-emotional competence over time in relation to the control condition [31]. Therefore, the results obtained from our research are comparable to those of other research carried out.

Therefore, the results obtained make us reflect on the need to include yoga within the educational environment; in this way, yoga would be part of the students' school life. For that, there is an essential component within all this process, and it is the predisposition on the part of the teachers to get involved in an active way within this process, because as it was verified in the investigation, yoga as an inclusive sport is not only a task of the teacher of the physical education area, but it is a task of all the teachers of the educational center. In this line, we emphasize the relevant and crucial repercussion in the future of a student that would have the inclusion of yoga in the educational field.

In general terms, the research presented has been carried out for a population of university students from the first to the fourth grade of primary education at the University of Jaén, as well as for the teachers of the province of Jaén, who work in primary education. In future research it would be acceptable to carry it out with Master's students, as well as teachers from other provinces of Andalusia, or even other autonomous communities, in order to correlate the data in different university levels and provinces and autonomous communities. In spite of this, although it is true that in a first moment, the objective of the investigation was "To analyze if it is possible to design a scale of perception that relates yoga, teacher training, sport, benefits of yoga, and the inclusive sport", given the results obtained and the high degree of correlation that has been obtained between the variables, the future investigations could be directed to determine which are the most beneficial poses of the yoga practice, as well as to verify which temporal duration has to be necessary per session, and in which temporal interval the benefits of yoga would be appreciable.

\section{Conclusions}

As a conclusion of the results obtained, the following can be mentioned. This research has been carried out in a sample population of 1191 students from the University of Jaén, specifically from the Primary Education Degree, from the first to the fourth grades of the course, as well as a total of 384 primary education teachers from public schools in the province of Jaén. The Likert scale has been built with an operationalization table, and dimensioned, according to the theoretical framework, in five dimensions and 30 items: A. yoga, B. benefits of yoga, C. inclusive sport, D. training of teachers, and E. sport The aim of this research was to analyze if it is possible to design a scale of perception that relates yoga, teacher training, sport, benefits of yoga, and inclusive sport. For the validation we have resorted to content validation, which was satisfactory, and construct validation, through the realization of an exploratory factorial analysis. The result of this analysis on the one hand confirms the relationship of our dimensions, and on the other hand reduces the scale by six items, obtaining a reliability according to Cronbach's alpha of excellent (0.901) and a Guttman coefficient of 0.850, also excellent, so it was validated in its construct. The Krulkal-Wallis test allowed us to determine that the data followed a uniform distribution, and preserved the null hypothesis, so we proceeded to the correlation analysis with Pearson's P, which allowed us to affirm, among many other results, that the sample population that considered that yoga should be implemented in the educational centers, also considered that its practice would greatly favor the acceptance of differences, promoting a climate of inclusion and equality in the educational environment in which they are immersed along with the students. In addition, 
a very significant correlation, which had a close relationship with the previous one, also referred to yoga improving the academic performance of students and also considered that its practice reduces the levels of competitiveness; therefore, the correlations mentioned above are marked within a climate of friendship, inclusion, and equality, far from the attitude that currently governs the schools, and that, in many cases, leads to school conflicts, bullying, etc., The contrast of hypotheses was made through an ANOVA, after testing the homogeneity of variances with Levene's test and Bonferroni's multiple comparisons, concluding that the null hypothesis was accepted. The confirmatory factor analysis was performed with structural equation modeling, giving an adequate goodness of fit (X2/g1 (5.05). IAA: GFI (0.93), RMSEA (0.071), NCP (794.95), SRMR (0.025), RMS (0.0053), ECVI (2.21). IAI: AGFI (0.80), IFI (0.99), NFI (0.98), TLI/NNFI (0.96), RFI (0.95), CFI (0.99). IP: PNFI (0.34), PGFI (0.31), AFGI (0.80)), so we can say that our scale was confirmed. Finally, the model was respecified to provide a future and innovative research line, being that the goodness of fit was correct in general (X2/gl (6.29)) IAA: GFI (0.92), RMSEA (0.081), NCP (423.69), SRMR (0.031), RMS (0.045), ECVI (0.85). IAI: AGFI (0.83), IFI (0.97), NFI (0.97), TLI/NNFI (0.95), RFI (0.94), CFI (0.97). IP: PNFI (0.51), PGFI (0.43), AFGI (0.83).

Therefore, the general objective was reached, confirming the relation between the variables, showing that in general yoga improves the academic education of the students. That's why the continuous practice of yoga generates an improvement in areas closely related to the academic environment, providing the students with a series of strategies that allow them to improve their academic evolution; but not only academic, the variables, in an individual way, show us a significant relationship between yoga and the improvement of the socializing process and/or personal development of the student.

Author Contributions: Conceptualization, D.M.M.; methodology, A.H.F.; software, D.M.M. and A.H.F.; validation, E.P.N.; formal analysis, A.H.F.; investigation, A.H.F. and E.P.N.; resources, D.M.M.; writing-original draft preparation, D.M.M.; writing-review and editing, D.M.M. and A.H.F.; visualization, E.P.N.; supervision, A.H.F. and E.P.N. All authors have read and agreed to the published version of the manuscript.

Funding: This research study received no external funding.

Conflicts of Interest: The authors declare no conflict of interest.

\section{References}

1. WHO. Statista. Available online: https://cutt.ly/trBWGqQ (accessed on 10 January 2020).

2. Rico-Díaz, J.; Arce-Fernández, C.; Padrón-Cabo, A.; Peixoto-Pino, L.; Abelairas-Gómez, C. Motivations and physical activity habits in university students. Challenges 2019, 36, 446-453.

3. Del Río, J.; Salazar, C.; Sánchez, A.; Flores, P.; Pineda, L.; Anaya, P. Use of yoga in improving body weight and peak expiratory flow of overweight and obese people. Euro Am. J. Sports Sci. 2020, 9, 45-54.

4. Hernández, D. Keys to Yoga. Theory and Practice; The March Hare: Barcelona, Spain, 1997; pp. 1-376.

5. Iyengar, G. Yoga for Women; Kairós: Barcelona, Spain, 2008; pp. 1-464.

6. Moss, A.; Reibel, D.; Greeson, J.; Thapar, A.; Bubb, R.; Salmon, J.; Newberg, A. An adapted mindfulness-based stress reduction program for elders in a continuing care retirement community: Quantitative and qualitative results from a pilot randomized controlled trial. J. Appl. Gerontol. 2015, 34, 518-538. [CrossRef]

7. Tong, J.; Qi, X.; He, Z.; Chen, S.; Pedersen, S.; Cooley, P.; Zhu, X. The immediate and durable effects of yoga and physical fitness exercises on stress. J. Am. Coll. Health 2020, 2020, 1-9. [CrossRef]

8. Smith, B.; Esat, G.; Kanojia, A. School-Based Yoga for Managing Stress and Anxiety; American Psychological Association: Washington, DC, USA, 2020; pp. 201-216. [CrossRef]

9. Luu, K. Comparing the Acute Effects of Hatha Yoga and Meditation on Executive Function. Ph.D. Thesis, University of Waterloo, Waterloo, ON, Canada, 2016.

10. Montero, B.; Carazo, P. Benefits of mental practice in sports. Phys. Educ. Sports Notes 2019, 135, 82-99. [CrossRef]

11. Rashedi, R.; Weakley, M.; Malhi, A.; Wajanakunakorn, M.; Sheldon, J. Supporting positive behaviors through yoga: An exploratory study. J. Posit. Psychol. 2020, 15, 122-128. [CrossRef] 
12. Moratalla, S.; Carrasco, A.; Sánchez, C. Yoga: Strategy for the improvement of coexistence and active participation in the social life of the educational institution in the early education stage. Education 2019, 55, 123-144. [CrossRef]

13. Reindl, D.; Hamm, A.; Lewis, R.; Gellar, L. Elementary student and teacher perceptions of a mindfulness and yoga-based program in school: A qualitative evaluation. EXPLORE 2020, 16, 90-93. [CrossRef] [PubMed]

14. Cooper, A.; Wolff, K. Young children's experiences with yoga in an early childhood setting. Early Child Dev. Care 2017, 189, 1397-1410. [CrossRef]

15. Kaur, R. Stress Free Education and Yoga. Stud. Indian Place Names 2020, 40, 2041-2047.

16. Cartwright, T.; Mason, H.; Porter, A.; Pilkington, K. Yoga practice in the UK: A cross-sectional survey of motivation, health benefits and behaviours. BMJ Open 2020, 10, 1-7. [CrossRef]

17. Swerdlik, J. Psychological Testing and Evaluation; Mc Graw Hill: México City, Mexico, 2001.

18. Blasco, J.; López, A.; Mengual, S. Validation of a questionnaire to ascertain interest in water activities. Agora Phys. Educ. Sport 2010, 1, 75-96.

19. Lawshe, C. A quantitative approach to content validity. Pers. Psychol. 1975, 28, 563-575. [CrossRef]

20. Tristán-López, A. Modification to the Lawshe model for the quantitative assessment of the content validity of an objective instrument. Adv. Meas. 2008, 6, 37-48.

21. Landis, J.; Koch, G. An application of hierarchical kappa-type statistics in the assessment of majority agreement among multiple observers. Biometrics 1977, 33, 363-374. [CrossRef] [PubMed]

22. Iraossi, G. The Power of Survey Design: A User's Guide for Managing Surveys, Interpreting Results, and Influencing Respondents; The World Bank: Washington, DC, USA, 2006; pp. 1-248.

23. Ferrando, M.; Goig, R. The Survey. The Analysis of Social Reality: Research Methods and Techniques; Alliance: Madrid, Spain, 2015; pp. 25-60.

24. Díaz de Rada, V. Types of Surveys and Research Designs; Public University of Navarra: Pamplona, Spain, 2002; pp. 1-243.

25. Kaiser, H.F. An index of factorial simplicity. Psychometrika 1974, 39, 31-36. [CrossRef]

26. Fisher, R. Statistical Methods for Researchers; Aguilar: Madrid, Spain, 1949; pp. 1-322.

27. Kaplan, D. Structural Equation Modeling: Foundations and Extensions; Sage Publications: Thousand Oaks, CA, USA, 2008; pp. 1-215.

28. Kline, R. Principles and Practices of Structural Equation Modeling, 3rd ed.; Guilford Press: New York, NY, USA, 2005; pp. 1-445.

29. Pandya, S. Yoga education program for improving memory in older adults: A multicity 5-year follow-up study. J. Appl. Gerontol. 2020, 39, 576-587. [CrossRef] [PubMed]

30. Neumark-Sztainer, D.; Wall, M.; Choi, J.; Barr-Anderson, D.; Telke, S.; Mason, S. Exposure to Adverse Events and Associations with Stress Levels and the Practice of Yoga: Survey Findings from a Population-Based Study of Diverse Emerging Young Adults. J. Altern. Complement. Med. 2020, 26, 1-9. [CrossRef] [PubMed]

31. Felver, J.; Razza, R.; Morton, M.; Clawson, A.; Mannion, R. School-based yoga intervention increases adolescent resilience: A pilot trial. J. Child Adolesc. Ment. Health 2020, 2020, 1-10. [CrossRef] [PubMed]

(C) 2020 by the authors. Licensee MDPI, Basel, Switzerland. This article is an open access article distributed under the terms and conditions of the Creative Commons Attribution (CC BY) license (http://creativecommons.org/licenses/by/4.0/). 